\title{
Cancer control in the first level: The role of rural nurses in low-income settings
}

\author{
Natalia Luxardo*, Ramacciotti K, Sassetti F, Billordo J and Alva L \\ University of Buenos Aires, Buenos Aires, Argentina
}

\begin{abstract}
This article is aimed at providing insights into the experiences of rural nurses' and their perceptions in relation to disciplinary values, particularities of the cultural context, institutional constraints in such settings, and the effects of other health systems on the day-to-day healthcare practices carried out in low-resource health centres. This study is based on a framework of equity used to explain such differences in access to preventive and adequate care, which result in different rates of morbidity and mortality among regions. Many researchers provide evidence to support the idea that persistent lack of accessible, affordable, and culturally relevant programs for cancer prevention and health promotion among medically underserved and historically marginalised populations are strongly associated with cancer disparities. Among underserved populations, rural communities are particular vulnerable in getting access to adequate cancer care. The daily work of nurses in rural settings can provide clues to help understand what happens between the broader organisation of care system directives and the daily routines carried out in health centres.
\end{abstract}

\section{Introduction}

This article is aimed at providing insights into the experiences of rural nurses' and their perceptions in relation to disciplinary values, particularities of the cultural context, institutional constraints in such settings, and the effects of other health systems on the day-to-day healthcare practices carried out in low-resource health centres and anchored in long-term studies on cancer inequity in Argentina.

The importance of the study of cancer in low and middle resources countries has been addressed by the World Health Organization which warns that the majority of the global cancer burden is found in such regions and calls for an initiative to tackle it by focusing priorities on the examination of the pillars of cancer control: prevent, treat, and/or cure cancers when possible, and provide palliative care when required $[1,2]$. Some of the common reported problems are advanced stages of diagnosis, the lack of early detection programs, the need to improve access, the lack of availability of quality cancer treatment centres, insufficient surveillance and cancer registry systems, health care disparities, poor infrastructure, a dearth of cancer treatment facilities, inadequate human resources and absence of resources for education and training in oncology and palliative care, the lack of access to preventive measures and treatments, which are scarce and inequitable $[3,4]$. Even when the burden continues to rise there are many efforts and initiatives to control cancer in these countries. One advance has been prevention programs to rural populations and the promotion of community based participatory research which engage not only local people but also primary care providers in the process. The integration of primary care providers into cancer control plans is crucial to avoid over-burdening the care system with an over-presentation of late stage disease, thus there are several incentives to work in rural locations [3].

This study is based on a framework of equity used to explain differences in access to preventative and adequate care, which result in different rates of morbidity and mortality among and within countries $[5,6]$. After decades of study, there is a consensus on the existence of social inequalities in health within many societies and links between social and health care inequalities have been examined $[7,8]$. Such studies based on the determinants of health that is the social and economic structures shaping health outcomes at the individual and population levels lead to the "health gradient", the inverse relationship between social position and health, likely the most salient findings on the social determinants of health [9-13].

As Angus, et al. (2013) sustain, even when most determinants of health and illness are situated outside the health care sector, they are deeply connected in the search for and subsequent access to care [14]. The importance of studying the health sector at different levels to address cancer inequities has been extensively proved, and the mechanisms by which disparities in cancer care are generated have been described in the literature $[15,16]$. Cristopher, et al. (2013) note that cancer inequities associated with cost, organisational, and transportation barriers are, at least in part, responsible for racial and ethnic differences [17]. Many researchers provide evidence to support the idea that persistent lack of accessible, affordable, and culturally relevant programs for cancer prevention and health promotion among medically underserved and historically marginalised populations are strongly associated with cancer disparities [18]. Among underserved populations, rural communities are particular vulnerable in getting access to adequate cancer care. Most of the services are provided in health centres located in the largest cities. Fewer studies have investigated avoidable causes of cancer, its impact in daily lives, how priorities employed to control the disease are implemented, and other related features [14,19]. While diagnosis and treatment are improving in urban settings, the rates of morbidity and mortality are increasing in many rural areas, with scarce or non-existent resources [20]. Sinding, et al. (2005) found that a

*Correspondence to: Natalia Luxardo, Iberá 19981 D (1429). Ciudad de Buenos Aires, Argentina, Tel: 541147822937, E-mail: palish@hotmail.com

Key words: nurses, rural, primary care, cancer inequity

Received: August 10, 2018; Accepted: September 24, 2018; Published: September 28, 2018 
common problem was the lack of communication among primary care physicians and the specialists of urban centres [21].

The investigation of Coughlin, et al. (2008) explores the relationship between the persons' race/ethnicity and the factors of the area in connection to health access, one of the most significant variables being the place of residence, rural or urban, with persons in rural areas having less controls. Broom and Assa (2011) demonstrated that in India biomedical cancer services are largely available to the wealthier cohorts of urban populations, whereas in rural areas there are often no treatment facilities or biomedical oncological expertise [19,22]. Gray and colleagues (2004) show that rural women chose cancer treatments that involved the shortest period of displacement from their homes, far from home and supportive networks, to avoid spending weeks while receiving radiation or chemotherapy [23]. Rural communities are more likely to be medically underserved, requiring patients to travel farther distances for care [24]. The consensus in the literature is that inequitable conditions, such as poverty and unemployment, interact to create health inequalities in rural populations that already face significantly limited opportunities [12].

Therefore, one of the first steps toward cancer control is an understanding of the nature of the cancer burden in traditionally ignored regions, such as rural populations, especially with respect to cancer care provision, human resources, overall impact, patients' perceptions, and cancer etiologies, for which social disciplines can provide standpoints that shed light over less known areas. In that sense, there is a consensus within academic literature about the role of nurses who work in the public health sector, especially in community health, for supporting healthy public policies even those oriented to socio-economical causes of illness and health which include social and economic exclusion, $[15,25,26]$. The daily work of nurses in rural settings can provide clues to help understand what happens between the broader organisation of care system directives and the daily routines carried out in health centres.

\section{Methods}

\section{Design}

The results of this study are drawn from a larger body of research conducted from 2015-2017 and supported by the University of Buenos Aires (Strategic Development Project, PDE 2015). Aimed at identifying symbolic and structural features of the sanitary system operating as deterrents or facilitators at different phases during the continuum of cancer control, the research, which is still undergoing analysis, focuses on the role of health centres of vulnerable peri-urban and rural areas in a province of Argentina (Entre Ríos, Diamante Department). The design was a collaborative study based on a wide array of mainly qualitative methods, according to the specific goals of each phase. The flexibility of this type of design was a requisite due to the uncertain contexts selected. Although our aim was to investigate cancer-related issues, we needed to be "open" to what was important for the communities analysed, such as unemployment, youth addictions, and environmental problems.

\section{Setting and population}

The geographic areas and populations of interest were located in a province of Argentina, Entre Ríos. We included selected medically underserved areas in peri-urban and rural areas. Only the analyses of rural health centres were included in this article. Due to the small communities, which may have easily identified the health centres involved, we decided to include three of them.
This study included three partners: 1) health personnel; 2) communities where the health centres are located; and 3) stakeholders and policy makers. In this article, we analyse the first group, with a focus only on nurses. They were four professional nurses: half of them women, two of them with a postgraduate specialization in Social and Communitarian Health. Three of them belong to the communities where the Heath Center were settled and all of them had more than 10 years of being rural nurses, but not necessary in the same institutions

\section{Interview recruitment and sample}

Reliability was the primary goal of the research. Informants were included through snowball sampling, whereby subjects themselves suggest others for recruitment. We also purposively selected individuals who would illuminate some questions that snowball sampling alone would not have addressed. The key informants in the health centres were nurses or social workers.

\section{Data collection}

As we aimed to investigate healthcare attention in rural areas through the eyes of the informants (personnel), we needed an approach suitable for such an emic perspective. In anthropology, an emic approach means that the researcher investigates how local people think and how they perceive the world in which they live. On the contrary, the etic approach is developed by the observer studying a social reality. Therefore, we mainly use a qualitative approach called ethnography, which can be defined primarily as a face-to-face type of interaction that implies an experiential immersion in our interlocutors' lived world. In this scenario, the ethnographer becomes his/her own and key instrument of data collection [27]. These experiences are modelled by the researcher's theoretical framework, but they can sometimes reshape the latter in unexpected ways, opening unexplored empirical as well as theoretical topics. The ethnographic endeavour is constituted by a bodily presence in the field, which supposes informal and formal linguistic interchanges (casual talk, open, and/or semi-structured interviews), participant observation, and the access of various kinds of written sources and documents.

Of course, the ethnographic method is not new in the field of healthcare [28]. However, in contrast with the sociology of health, this method has not been extensively used to study the perspectives of professionals, particularly nurses. Ethnographers try to find informants who constitute a crucial link between the observer and the observed society. The informant is much more than a person providing information; he or she is a "translator" and the "medium" between the observed society and the ethnographer. The informant can clarify the meaning of various components under investigation. Field-workers typically learn the local language and the rules of behaviour to be unobtrusive, so that the informants will forget they are being observed and act formally. Data are collected mainly through observation, dayto-day conversations, and interviews. Anthropologists struggle between the need to be neutral observers and the importance of being close to those being observed through friendship and mutual trust. Given the need for a broad collection of information, the interviews conducted by ethnographers are ideally unstructured and follow the path of a conversation and multiple techniques of inquiry are used to obtain a clear view of the prevailing corruption practices [27]. Bureaucratic itineraries involve analysis of real bureaucratic activities from various angles. These include long periods of research, the use of participant observation (with multiplication of social interactions between the anthropologists and the observed), comparison, personal diaries, and informal interviews with the purpose of developing a clear account of nurses' perceptions of standard practices. 
In-depth interviews with key informants were conducted, with open respondent-led conversations where questions emerged from the immediate context. We conducted repeated interviews with the same respondent, with the purpose of allowing a deeper understanding of their perspectives. These were combined with semi-structured interviews, with topics focused on practices. The purpose of the interviews with the nurses was to elicit an account of their daily work in health care settings, especially during their professional activities at the institution. Even when record-taped was what we most of the time do, some felt constraint to talk freely and explicitly request: "To answer the question you just asked me, I would rather my answer not be recorded". These off-record narratives were the richest in relation with the type of information offered, the dimensions identified, and the problems and responsibilities exposed.

We also conducted interviews in natural groups that spontaneously emerged, which always occurred with a traditional kind of green tea that is shared as a pipe, called mate, and is very common in South America [29]. In a few situations, we had to decide in situ to implement joint interviews because it was the only way to interview a specific person. We noted that in cases when another staff member was present, topics such as dishonest or negligent practices were much more explored and accounted for, as they were encouraged by the feedback that arose in such an informal setting.

\section{Data analysis}

In coherence with the chosen method, we analysed data inductively, that is, without a firm hypothesis to prove but instead open to what arose during the interviews, field notes, and participant observations. We had a focus, but the themes arose later, following analysis. Most of the themes were not included previously, including personal trajectories as nurses, issues related to conflicts within small and endogamic communities, and the history of the places and persons in the communities. These were excluded in this analysis to adapt to the purpose of this article. Indepth interviews and open-ended questions enabled us to understand the social and cultural context in which daily decisions were made and we relied upon coding according to the axis of the study but also included "residuals" an important part of the analyses.

We systematically read, reviewed, and discussed each interview and fieldwork notes several times, and searched for general trends and patterns within the data collected. During this process, we continually sought to retain the richness of the respondents' experiences, documenting atypical cases, and conflicts and contradictions within the data. Interviews were coded to search for more refined concepts that could explain dimensions not previously analysed. Grounded in the heuristic, we searched for new empirical theoretical concepts that could help explain the daily health care routines in patients with cancer.

\section{Validity}

To verify the validity, we used a method known as member checked, which simply confronts key informants with interpretations and analyses. Due to the relatively small sample and the fact that some of the informants were included as internal researchers of the study it was easy to share personally, by email, skype or phone calls, the main results that arose from their participation. In many cases, some aspects of a particular interpretation were reviewed and, in a few cases, some verbatims were removed because interviewees believed they did not clearly express what they intended to say. In most of the cases, we used the data and interpretation as it was in the transcript. Subsequent exchanges of views within the research team contributed to our understanding of some of the narratives.

\section{Ethics}

The primary study was approved by the Central Bioethics Committee, Health Ministry of Entre Rios in March 2016.

\section{Nurses in Argentina: A general framework}

Even though this research is based on ethnography, to address the particular perspective of nurses as a common matrix that involves all informants regardless of the institution to which they belong a brief historical review of this profession in Argentina is necessary for a better understanding of the current situation. Thus, by emphasising their academic training and their role within the health system we can derive a common field with their problems and potentials, despite minor differences.

Nursing is a profession that contributes to health and physical safety and the development of cognitive, physical, and emotional skills. Nurses take care of sick bodies: feed them, clean them, control them, provide medicine, handle complaints, provide moral support, and await the most possible dignified death. In spite of administrative tasks and high technology treatments, the body work and the relation and interaction with the community is still the personnel's goal and, at the same time, the patients' requests [30,31]. It is a work activity embedded in the complex structure of the health sector, characterised by the existence of a sanitary structure with evident territorial inequalities and based on three cornerstones: the public sector, health care providers, and the private sector. The public sector focuses on direct provision of the service by means of a hospital network and other peripheral centres providing coverage, which attempts to be universal, free of charge, and available for persons of all nationalities, both documented or undocumented.

The source of funding is public. The national system of health care providers benefits workers with employment contracts. The private health system is made up of a group of companies whose funding is based on their affiliates' monthly fees. Within this heterogeneous scheme, fragmented and unevenly distributed in terms of territory, it is the public sector that covers half of the population's health needs and thus, it is also the sector that has created more nursing jobs [32]. The public hospital entry system for nursing personnel is subject to a selection system based on merit. There are also appointments to rapidly meet needs. The ideal of envisaging a system based on merit and professionalism has its historical roots with Cecilia Grieson and the creation of the first professional school. The first graduate of Medicine from the University of Buenos Aires (1889) organised a series of courses about first aid and caring for the sick. These classes were for the personnel who worked in Buenos Aires hospitals and sought to improve care and attention practices based on a model created by Florence Nightingale. Nightingale's proposal was founded on three pillars: the management of the school would be run by a nurse and not a physician; the selection of candidates would focus on physical, moral, intellectual, and professional aspects, and the school would teach methodical and constant education, both in theoretical and practical aspects [33].

The classes taught by Grierson constituted the kickoff for the creation of Escuela de Enfermeros, Enfermeras y Masajistas (School of Nurses and Masseurs) in 1912, which was in the city of Buenos Aires. Even though this school was initially for men, after a couple of years the occupation become more feminine based on the reasoning that it was the feminine condition and the allegedly natural instinct to look after women that benefitted this profession. In addition to this first undertaking boosted by Grierson, the creation of the Nursing Schools 
depended on ethnic hospitals, the schools promoted by the Red Cross and the schools created during Peron's government. Since the 1950s, training spaces at various universities have been launched in an attempt to increase enrolment and improve teaching quality to face the demands posed by the creation of hospital centres, the challenges of modern technology, the caretaking so-called "modern" diseases demanded, such as cancer, cardiovascular disorders, diabetes, and mental diseases, and the tasks resulting from endemic and epidemic disease prevention campaigns. The addition of nursing to the university system represented a qualitative leap as it implied a way of mobility, of social promotion, and aimed to prioritise the profession.

Throughout history, the feminisation of nursing in Argentina has only strengthened. The greater acceptance of women in areas connected with caretaking has been linked to the fact that these interventions are associated with an extension of the quality's nature has gifted women and thus, women were tied to these activities, and not to the job itself. The conception of nursing as a vocation, related to the care of someone else as a "natural role" is contradictory with nursing as a profession, a qualified job that can be conducted by any qualified person regardless of gender. Therefore, while the service vocation demands social recognition as retribution for the tasks performed, professional labour training implies an economic retribution in accordance with professional status. It is known that caretaking demands time, knowledge, complex social relations, as well as loss of energy (both emotional and personal). Its specificity is based in its character and relations, at the same time obligatory and selfless, and gives a moral and emotional dimension evidenced by the assistance and service provided [33]. This characteristic, as Nancy Folbre (2001) points out, limits the nurses' job demands, as they have a limited capacity to be on strike since labour actions might threat the wellbeing of their patients, and therefore, they are "love prisoners" who look attentively at labour rights behind the bars as they are in this dichotomy, which are not always easy to solve [30].

The tasks connected to caretaking are related to ideas of sacrifice, in the common sense, and that idea is functional to keep salaries low or ad honorem. In fact, when considering these interventions as part of their natural conditions, there has been a devaluation of tasks, and as a result, a disregard of their training and labour rights. The nursing staff, even those with additional qualifications, have been recognised and valued, both socially and economically, in comparison with other professional fields and must prove at all times, consciously and unconsciously, that they are qualified to fill the position and face the stigmas and stereotypes. Throughout history, training programs have added more technical content and class hours for professional practice. This training seeks to improve the teaching quality, so trained nurses can face the complexities of prevention, diagnosis, and treatment. However, in reality, practice situations emerge in which nursing personnel are given increasingly specific technical tasks, as well as a variety of administrative and cleaning activities that result in work overload, stress, and overall unhappiness as their salaries do not match their increasing responsibilities. Likewise, even though they conduct various tasks on a daily basis and have a wide margin for decisionmaking, in many cases, as a consequence of physicians' absences in the hospital hierarchical structure, it is the health personnel the one having more social prestige, higher salaries, and better work benefits [34].

\section{Results}

We will break down the investigation results in three aspects: Firstly, the characteristics rural contexts have. Secondly, the role of nurses in the institutions as well as their relationship with the rest of the health personnel and management. Finally, aspects concerning the health services' organizational forms.

\section{Rural contexts: Away from the world}

As the first significant point of the inquiry, we can find the problem related to the place access as it has no paved roads, some houses are placed downhill, some are flood-prone areas next to the river, professionals are absent when it rains, and ambulances cannot reach the place. When transporting in adverse weather conditions, they're completely without resources. As regards schedule, nursing staff are sent just to be in the centres for six hours. Even when formally there are other people with similar hours of job, we notice during the ethnography constant absences of other professionals except nurses. In times of natural disasters (such as floods), people are told that in case of emergency to seek care in urban centres they have go through the river, or using horses and carts, since there is no ambulance or transport to access those places. The expertise in Community Medicine postgraduates enables some nurses to cope with these situations, for example, by putting nylon stockings and bags on their boots in such a way that prevent water or mud from passing, just as they learned to manage in boats.

"We have no radio. I use my small phone. The municipality brings me here. Because as you imagine I will not come on foot. I am 50 years already ... I come at 7:30 to be here at 8".

"The access part people have is very complicated, because it has no access to care on rainy days, it is impossible here. It is the people who say it. For entire weeks people cannot leave their house; we are away from the world."

"When there is an emergency and is flooded, those who need medical attention are transferred on that same river. If not, they are ridden on horseback, until the road. Here we are away from the world. It is a swamp".

"Nobody [authorities] comes here, not even when we had the storm they promised they were going to come to see what had happened. Everything is done through enormous effort. The truth is that with a small population density, 300 people do not make a difference, they are not worthy in terms of politics."

In the most disadvantaged rural centres there were moments in which they did not even have basic things, such as water to wash their hands. In the interviews conducted, when we investigate with the nurses on this matter, we detected that responsibility, although subtle and with euphemisms, was given to the health personnel of the center, mainly by the managers who were in charge, instead of attributing the lack of interest to the municipalities which claimed "they cannot guess what happens here" when no one told them. This lack of commitment for other health care workers who are in rural centres "merely for the salary" is permanently noticed by those who are there, who fulfill the job and who give their profession a social value of relevance that is unfairly ignored, a concept we will cover later.

"I think the need has always been here, but probably out of fear those who were in charge of this didn't speak, they just said everything was $o k$ and it is not ok. There is no water, I came and there was no water here. I cannot work in nursing without water, I told them [authorities]. The first and second day I came, I went to the street and people had no water either. Authorities didn't know the issues we had here, there were some broken pipes. Why didn't they come to fix it? Because there was no communication, there was no interest from those who were working in the center". 
These contexts have health realities of extreme vulnerability, in which there are people who live from hunting and fishing, and only have some subsidy as a means of life (by disability, social security, among others), with malnourished children, going through poverty diseases (such as brushwood). At the same time, residents' housing conditions are extremely precarious, bathrooms are outdoors and the roof -made of material - might be missing, with awning flown away by storms. In this sense, nurses who know and have walked these places, recommend retrieving local knowledge, people used to have before, such as adding lime to the constructions to combat the spread of the vinchuca (the triatoma infestans, a bug which transmits "Chagas", an incurable neurological disease that can result in death).

"Lime is the best. With the other chemical you kill the vinchuca, but the poison also goes straight to the people. I mean, we must do the natural thing that was made before. Retrieve folk knowledge from communities".

Other issues that are gaining ground in the health personnel speeches are the environmental factors, especially in these areas where the toxic agrochemicals in the fields and plantations surround the health centres.

"They were drawing water from a slope of 'natural water'. It might be from the slope, but it washed all the neighboring fields, full of chemicals"...

We observe that nurses have "the pulse" of what happens locally, what people do not dare to tell doctors. They take care not to reproduce expelling practices of medicine, such as to use inexplicable technical jargon, unequal positions in the relation which only separates. Nurses spend a lot of extra-time to re-translate into simple and clear terms the medical explanations about health care people receive in the center. They also develop strategies that are practical to bring people to the health center, as can be noticed in the stories below:

"People tell you everything here. You cannot be completely honest... it would make a barrier, they might think: 'This one wants to change everything'. So, you must work with them very carefully and humbly, step by step, assessing their problems but putting yourself at the same level, not above. The way you are dressed and the way you speak have a lot of influence in these interaction".

"I'll talk about these things, but it's going to be Greek for the person who probably thinks: 'What is this fool telling me? She is an arrogant'. You can talk to them about problems on the skin, the breath for the brushwood, the cardiac diseases related to the style of life, the lack of information and education and cases of the Chagas disease, but it has to be in a simple way".

\section{The role of nurses in rural institutions: "We deal with all kind of problems"}

One of the most notorious aspects is the number and variety of tasks nurses must perform. This exceed widely the functions for which they are paid and their areas of professional competence. These tasks include administrative activities (such as answering calls, giving appointments, etc.), cleaning activities when the cleaning staff are absent, or even to diagnose and take care of patients when the appropriate human resources are not present.

"Doctors don't always go. People come to the institution looking for answers, sometimes there are extremely basic issues unresolved, so I have to do something. Of course, I know I am not authorized to diagnose or prescribe medicines, but it's that or nothing. Here is a chaos. People don't even have means of transport, that's why I have to help in any way, even cleaning".
Of all the tasks they carry out, there is one of utmost importance and that is to keep medical registries. There is no doubt regarding the importance given by nurses both discursively and rationally as to why keeping registers on time and in order in vital. For example, having accurate diagnoses of what is going on, keeping track of patients, knowing the population and its problems, being able to foresee and plan based on the database are some of the advantages mentioned.

"I couldn't find data, there weren't any information when I get here. So, I am making a kind of informal frame to get access to basic information about patients. I'm not talking about medical records, the physicians' sheets... a luxury for this place. But I learn to deal health problems with evidence, so I want to have statistics... to know the number of children we have, how many are under their weight, when they are at risk and so on".

However, on an institutional daily basis, this time to keep registries does not generally exist. With not personnel, the data uploading tasks, as well as other tasks, fall on them almost entirely. When the doctors have to fill them in, they delegate this task; that is why they do them from time to time, sometimes they start but do not finish. It is a completely heterogeneous situation according to the health center. We spotted disbelief regarding the importance data has for a health system which does not use them, wondering why having data that "never returns anything given" or at least they are not used to improve the situation of the centres. At the same time, they distrust the records since they know that when in a hurry, things can be made up. That is why data is basically an exchange good. They generate data whenever they have to request something from the Ministry of Health, as they know that if there is not data, it is hence invisible, with all that entails (not complying strictly to the reality but being "enlarged" or "diminished" depending on the impact needed to show to get a specific supply).

"Here you need full time administrative personnel. You need someone to fill in data because if you don't have a reference data, data collection, they [authorities] will ignore your requests for any resource. They would say: 'I believe you, but I need your request written".

"It's strange that children with measles do not appear in statistics, because you see them. Well, maybe statistics are... let's say, invented in a way".

"That's the reason why I send the forms inventing low weight, but kids are vulnerable, and I need to give those mothers the milk we have. To tell you the truth, I do not analyze the milk regulations strictly because these people must have at least one kilogram of milk powder in their house. As a mom told me: 'I can't give my son only black tea for breakfast'".

"That's another of the things that happens. The authorities give you lots of things to fill in, but there is no time to fill them in. I ask the gynecologist to fill them in, and probably he has ten patients, one after the other during the entire day of attention, so he throws the form at me. We eventually end up doing them, because when we have to go and get speculum..."

With regards to the nurses' specific training, we found during the fieldwork ideal specializations for rural contexts, as there are several with postgraduate programs in Community Health. However, many times they are confined to institutions and cannot develop the activities for which they were trained since the basic conditions to do so are not given. For example, they cannot go out to perform home care visits because they do not have administrative staff that "replace" them when opening the health center. Nurses neither have record systems to upload this type of activities nor data related to the patients and home-made forms are completed, many times lost. Health promoters and agents 
are continuously transferred due to management changes and thus the human resources that would complement these activities are lost. At the same time, they consider these activities are just one link in a long chain of health care. Therefore, when the staff identify that the tasks needed to conduct the following steps are not planned or foreseen, such as the referrals of specific cases detected, the importance of the activity of home-care visits become blurred and meaningless, because there is nothing they can do, but to feel empathy with what is really going on in those contexts. The examples that follows describes this outlook:

"In community nursing, going to the field is essential. I like it, but I don't like walking alone, you must walk with someone. Then, you return to the institution, and you show the people the problems of the families, what is happening on the ground. I bring the patient up here, but then I need someone to transfer him/her where needed. I take the data, but then I send it to you [to institutional directors] to do something with that, because they know where you to go and who to talk to. I am the visible face for the families. We must walk the streets, we are not going to find things out, unless we walk the streets".

"If they don't come, we look for them according to the medical history we have here. We go out and look for them. That's why I believe we need another person to stay here or who goes with me while someone stays here, so I can walk the streets more. I don't want to close. That's another barrier, especially because I don't want to close here since people are just becoming used to coming here".

"The authorities should have more sensitivity. What you see as important it is in the field, you don't see it behind a desk waiting for people to come".

\section{Organizational types of the rural health centres: "I do what I can, and what I cannot... I invent it"}

Rural health centres cannot be treated as a homogeneous block since they vary in aspects such as the size, the type of institutional dependence, the real opening hours and the ones who truly follow them, the specialists they have, the institutional values and of course, the communities. On this point, what is expected of the role of the primary care level is clearly identified by the nursing staff. A person sarcastically mentions that someone has to have it clear because the new director of primary care does not, he not only just come directly from the private sector but is also a kidney specialist (nephrologist).

"We have to encourage the promotion and prevention and not let the disease settle. We must pay more attention to promotion and prevention. This is a vulnerable area."

The type of unit (municipal or provincial) evidences notorious differences between the centres in terms of the available resources they have. During the fieldwork, we identified continuous threats regarding the units' changes according to the changes of management, with opposing views. For some people, being transferred from a provincial unit to another municipal is clearly a step behind because the municipalities have fewer resources, whereas for some others it represents an opportunity since they will have more autonomy to act. At this point, the lack of resources or the volatility in their provision that can result in stopping the provision of certain supplies fuels the nurses to conduct all kinds of creative initiatives to cope with those deficiencies that would affect the sick. Among these faults, for example, we can include the need for human resources, such as psychologists or social workers. We found nurses who take listening to people's problems seriously, not just those related to the medical intervention only but also in relation to emotional and social problems, considered to be another of their tasks and in which they provide guidance and counseling, often for the understanding and rapport that belonging to the same area or being closer to the population in the social level brings about. Management to specific socio-economic problems (such as those relating to subsidies, universal child allowance, unemployment benefit, housing problems, disability) which are daily thanks to the lack of psychologists, is strengthened by the fact that many people are form the same place and social class as nurses, and hence they see them closer, trustworthy and more available than the medical staff.

Not all rural health centres have the same specialists among medical professionals, but they have different specialties, such as clinical medicine, pediatrics, cardiology, gynecology and obstetrics, mainly. It is common that when women go for their children' health problems or age controls, nurses "get" them with reminders (such as matching the appointment for the same day) for the control and care of their own health, usually in connection to sexual and reproductive health and prevention of cervical cancer, etc. The smear tests are conducted in many centres by professionals in obstetrics. This specialty had been considered "inadequate" by gynecologists, according to the interviews, but in this type of context it is okay. In the case of males, medical personnel highlights that you cannot delay the attention because they do not return, so you must summon them straight away, from one week to another, so as not to lose them.

Unlike what generally happens on urban centres, here nurses "go out to find" those women who miss an appointment for the smear test, for example, since as most respondents agree, they "almost never" miss their children's controls. This activity is continually stressed as vital in these contexts. However, it is limited since they cannot close the center to go to the "ground" as that would prevent the rest of the community from having access to health or because they are sent alone to do so and there are places where they need to go with someone, especially if a problem arises in uninhabited areas. Going to the ground, being there is essential to understand what happens in those places, "it gives you sensitivity".

The opening hours can be a highly contentious issue for the staff, because whenever they extend them, nurses know they are the only ones who will comply with that strictly. In impoverished rural areas, hours are more limited ( 8 to 13 ) and the staff must have their own vehicle - since no public transport can get there- or the municipality puts vehicles at their disposal to pick them up, such as for the nurse who opens and closes. All the rural centres in which we carry out the fieldwork have in common the nurses' continuous complaints in connection to the non-compliance schedule of doctors. In extreme areas, we observed that it boils down to a quarter of what is stipulated. So much so that some nurses have a kind of agreement with the people who have appointments and warn them- through a neighbor - if it is not the time yet to avoid unnecessary transfers. Leaves and sudden absences are common. With this outlook of "erratic" resources, nurses perform small tricks so that people are not left without attention, such as providing more appointments than those physicians established in their agenda and then call it spontaneous demand. This practice is also common among the population that "spread the word" when they know the professional is working. Sometimes in a paternalistic way, they advocate for people they know their difficulties, "I begged the doctor to give him attention", but this is clearly a point that causes frustration since they see what actually happens and what could be solved in the center. We have to add those cases in which physicians are absent due to personal problems, unexpectedly, which brings about chaos for the nurses who are there and must deal with this, which in extreme cases 
has led to violent situations with the population that is suddenly left unattended (insults, complaints).

"You need a doctor, at least 4 hours every day, you saw the amount of people that came in a while. The physicians' appointments are already full, what shall I do with the other people?"

"We fell short of it, that is why 12:30-12:45 we have to stop because we have to go there to comply with the other schedule too. Otherwise, you keep providing service and people keep arriving. You can see to magnitude of the need. Everybody comes, and more show up. When the first person assisted leaves, he tells the neighborhood... ".

"We have to comply with our work load, we are here from 7 to 13 on a daily basis whereas managers work 16 hours... a month!".

"The doctor comes at 9 maybe, and even if there are loads of patients, she just sees the ones she says are her share, and then goes away and leaves them unattended. She comes at 9 and by 10.30 she has already left. On top of that, they are absent every now and then".

"Today the doctor could not come for a personal problem, so she told me to change her appointments for Friday. Then, today's appointments were changed to Friday, the ones I could... we always fall short. I have to stop at some point, because otherwise you keep on working and people keep coming".

"If it rains it's a lost appointment. Adrift. Or it is suspended, or you promote coming another day if there is time, if not well..."

In better positioned rural areas, we have seen changes in opening hours, e.g. 12 hours, to facilitate access to everyone, but the personnel see it as a way to break them, since they can never meet other professionals, debate cases, etc., because to cover this time range, all the agendas have to be adjusted so as not to leave attention potholes. This compression between the population medical care supply and demand results in nurses taking over a thorough "implementation" of the process. They precede the physician in the service and pave the way to make the medical intervention as accurate specific and rapid as possible, so that they are discharged and more can be assisted. They prepare patients and leave them ready.

"There are a lot of things to do with the patient before sending patient to the doctor. I want to give him with the least number of nursing things possible, which is my task, and I will elaborate on a piece of the medical history. Then, the physician sees that and focuses more quickly on the patient. As the physician has high demand I don't want him to waste time".

One of the recurrent features we observed during fieldwork in all the health centres involved was the priority personnel placed on the protection of their positions at the organisation, which were considered extremely fragile. Only after several months of returning for interviews and observations where they were "open" to genuine perspectives, which included frustration, anger with the authorities, lack of belief in the fairness of the health system, and resignation. In this sense, intraorganisational friction among hierarchies and functions of personnel was apparent, in which an inversely proportional equation was apparent with nurses at the bottom of the organization chart of the health team but at the top of responsibilities when compared with other professionals, not only medical doctors. These frictions were related to time of service, competences, and setting health priorities. For example, despite provincial and national directives, what is addressed when setting health priorities within the organisation is influenced by the directors' own interests, which concentrates efforts on problems more related to director specialisation than what may be relevant for the community. Hours of health services are set for the convenience of directors or medical doctors, not nurses or patients. They feel part of the community in many aspects.

Nurses feel constraints to intervene in health emergencies since they are not legally allowed to do so, but they addressed the impotence felt when these needs are not addressed due to the frequent unavailability of medical doctors at stipulated times. According to fieldwork registries, doctor availability is even less than half of what it should be according to the administrative structure of the organisations. There is a stand with the lack of titles that would allow them to legally protect for intervening that has a paralysing effect on services: those who are available cannot intervene. In many cases this ad hoc time reduction decided on by professionals and directors made is informally established and they organise turns with this consideration. But frequently sudden absences made professionals not available according to the stipulated schedule, resulting in a patients' trip made in vain, which, depending on the geography can be more or less difficult. For instance, one health centre is at the top of a hill, so patients on the riverside have a short but difficult "climbed trip" for getting assistance. Considering that patients are often pregnant women or have small children who must be carried, the anger of nurses when dealing with situations such as these is not surprising.

\section{Conclusion}

In this article, we aimed to contribute to emergent understandings of healthcare attention in rural settings through an in-depth analysis of the perspectives of nurses. By focusing on the 'ongoing activities of actual individuals' as Smith (2005), McCoy (2008) and Sinding (2010) with institutional ethnography, we can conclude that nurses serve as a buffer against health inequity in rural settings [35-37]. There is evidence that poor rural nurses are more likely than urban nurses to be isolated without resources in settings of multiple constraints, and research on health personnel has already shown a linkage between various characteristics of practice settings and the stress, fatigue, and emotional exhaustion of healthcare providers affecting a required well-being for proper conditions to do their job, in settings where urgent making decisions and a blurred priority-setting from directives lead to a constant pressure within the health personnel $[38,39]$. FalkRafael and Betker (2012) report that short-sighted planning, continual restructuring and changing priorities of the public health system affect nurses' efforts, and increased workloads, lack of resources, administrative constraints leave nurses feeling powerless, and a sense of apathy that undermines their attempt to achieve change as well as their sense of purpose regarding their profession [26].

This research shows that despite such constraints nurses' strategies during day-to-day interventions are usually the main nexus between health centers and community implementing informally an effective process of enhancement of basic health system in rural areas. The practice of nursing, although throughout history a notorious interest in improving the quality of education in the curricular formation and modernization of their practices is noticed, in practice, situations are still characterized by a multiplicity of tasks, work overload and a hierarchical and unequal relationship with the medical staff. An interest in approaching the popular knowledge and looking for mediators in the local community who facilitate communication with the communities can be perceived.

These results show that most of the first level of attention effort is located upon nurses' responsibilities, either assumed by a strong commitment with their discipline values or assigned by default due 
to the sanitary system gaps at that invisible level: they are the visible and permanent face of the sanitary system in rural areas. They spend a much greater amount of time at the institutions compared with any other professional and have comprehension of both social worlds (biomedical and folk world) and the rules, expectations and possibilities of each, as well as adaptive and creative strategies to deal with restrictive settings, and the sensitivity to get the "pulse" of the mood of the local community.

This study presents important issues for further analysis. The institutional limitations detected in primary health care initiatives demand an urgent call to review healthcare settings in rural areas that are by far much less studied compared with urban health settings. Cancer policies need to be driven by equity. These findings also illustrate some possible directions for future policy making. The emphasis on desk official guidelines and programs' protocols conducts to a lack of knowledge or blindness for deeply considering the role of contexts and how these programs can be "adapted" to real conditions, which needs more focus including some of the personnel in a symmetric relation as co-researchers when is possible. Another interesting topic for future analysis is the way that these small daily decisions made by nurses' impact other sanitary personnel.

The characteristics of this research also present some limitations. The most notable is that some "eclectic" theoretical and methodological approaches have been used, which were considered suitable for accounting for the different dimensions of the phenomenon. A brief history of the nursing profession to explain them as a group within a bigger system, symbolic anthropology to provide insights to understand the not-explicit, "obscure" sides of health attention, approach taken previously and sociological and public health approaches, which might be fruitful to explore but not measure. Thus, future studies could concentrate on fewer dimensions within a single approach to obtain more structured data. Another limitation is the unknown bias in the purposive sample because of health workers that refused to be interviewed or participate because of subtle pressure they may have felt, considering a perceived and objective socio-professional hierarchy in the structure of health personnel teams. Moreover, the relatively small number of staffs selected could limit the scope of the results, but "open" dimensions and a deeper understanding of the phenomenon was. A study with a larger sample would provide more evidence on the ways in which nurses interact with team members and patients in such contexts. Finally, this research sheds light only on a small aspect of the healthcare inequity, although if combined with other perspectives that include proximal and distal determinants outside the health sector (e.g., environmental factors, macroeconomic factors, socio-demographic factors), a better understanding of the whole picture could be obtained.

\section{References}

1. World Cancer Report (2008). International Agency for Research on Cancer / WHO, Lyon.

2. Ginsburg O (2014) International Women's Day 2014: women's health equity is progress for all. Ecancermedicalscience 8: ed33. [Crossref]

3. Lokody I, Collingridge D (2015) Latin America: rising to the challenge of cancer control. Lancet Oncol 16: 1399-1400. [Crossref]

4. Farmer P, Frenk J, Knaul FM, Shulman LN, Alleyne G, et al. (2010) Expansion of cancer care and control in countries of low and middle income: a call to action. Lancet 376: 1186-1193. [Crossref]

5. National Academies of Sciences, Engineering, and Medicine (NASEM) (2017). Communities in action: Pathways to health equity. The National Academies Press, Washington.

6. Braveman P (2006) Health disparities and health equity: concepts and measurement. Annu Rev Public Health 27: 167-194. [Crossref]
7. Beckfield J, Olafsdottir S, Bakhtiari E (2013) Health inequalities in global context. Am Behav Sci 57: 1014-1039. [Crossref]

8. Armstrong P, Armstrong H (2003) Wasting away: the undermining of Canadian health care. Don mills, Ontario, Oxford University Press.

9. Marmot M (2005) Social determinants of health inequalities. Lancet 365: 1099-1104. [Crossref]

10. Braveman P, Gottlieb L (2014) The social determinants of health: it's time to consider the causes of the causes. Public Health Rep 129 Suppl 2: 19-31. [Crossref]

11. Frohlich KL, Ross N, Richmond C (2006) Health disparities in Canada today: some evidence and a theoretical framework. Health Policy 79: 132-143. [Crossref]

12. Hankivsky O, Christoffersen A (2008) Intersectionality and the determinants of health A Canadian perspective. Critical Public Health 18: 271-283.

13. Raphael D (2006) Social determinants of health: present status, unresolved questions and future directions. Int J Health Serv 36: 651-677. [Crossref]

14. Angus J, Lombardo E, Lowndes R, Cechetto N, Ahmad F, et al. (2012) Beyond barriers in studying disparities in women's access to health services in Ontario, Canada: A qualitative metasynthesis. Qual Health Res 23: 47-67. [Crossref]

15. Cohen BE, Marshall SG (2017) Does public health advocacy seek to redress health inequities? A scoping review. Health Soc Care Community 25: 309-328. [Crossref]

16. Gould J, Sinding C, Mitchell TL, Diana LG, Ito Peng, et al. (2009) 'Below their notice' Exploring women's subjective experiences of health system exclusion. Journal of Cancer Education 24: 308-314.

17. Christopher JK, Chen J, Dagher RK, Holt C, Thomas SB (2015) Decomposing differences in medical care access among cancer survivors by race and ethnicity. Am J Med Qual 30: 469-479. [Crossref]

18. Gwede C, Ashley A, McGinnis K, Montiel-Ishino FA, Standifer M, et al. (2013) Designing a community-based lay health advisor training curriculum to address cancer health disparities. Health Promot Pract 14: 415-424. [Crossref]

19. Broom A, Assa D (2011) The rise of cancer in urban India: Cultural understandings, structural inequalities and the emergence of the clinic. Health 16: 250-266. [Crossref]

20. Caldwell P, Arthur H, Rideout, E (2005) Lives of rural women after myocardial infarction. Can J Nurs Res 37: 54-67. [Crossref]

21. Sinding C, Wiernikowski J, Aronson J (2005) Cancer care from the perspectives of older women. Oncol Nurs Forum 32: 1169-1175. [Crossref]

22. Coughlin SS, Leadbetter S, Richards T, Sabatino SA (2008) Contextual analysis of breast and cervical cancer screening and factors associated with health care access among United States women, 2002. Soc Sci Med 66: 260-275. [Crossref]

23. Gray RE, James P, Manthorne J, Gould J, Fitch MI (2004) A consultation with Canadian rural women with breast cancer. Health Expect 7: 40-50. [Crossref]

24. Leipert BD, George JA (2008) Determinants of rural women's health: a qualitative study in Southwest Ontario. J Rural Health 24: 210-218. [Crossref]

25. Falk-Rafael A (2005) Speaking truth to power: Nursing's legacy and moral imperative. ANS Adv Nurs Sci 28: 212-223. [Crossref]

26. Falk-Rafael A, Betker C (2012) Witnessing social injustice downstream and advocating for health equity upstream: "the trombone slide" of nursing. ANS Adv Nurs Sci 35: 98-112. [Crossref]

27. Wright $\mathrm{P}$ (1994) Existencia, Intersubjetividad y experiencia. Hacia una teoría-práctica de la etnografía. Runa XXI: 347-380.

28. Pelto P, Pelto G (1996) Anthropological research: The structure of inquiry. Cambridge University Press, Cambridge.

29. Coreil J (1995) Group interview methods in community health research. Med Anthropol 16: 193-210. [Crossref]

30. Folbre N (2001) The Invisible Heart. Economics and Family Values. The New York Press, New York.

31. Tilly C (2000) La Desigualdad persistente. Manantial, Buenos Aires.

32. Ramacciotti, K (2010) Los dilemas irresueltos en el sistema sanitario argentino. In A. Cannellotto and E. Luchtenberg coord. Medicalización y Sociedad. Lecturas críticas sobre la construcción social de enfermedades. UNSAM Edita, Buenos Aires.

33. Ramacciotti K, Valobra A (2015) Feminización y profesionalización de la enfermería 1940-1955. In C. Biernat, JM. Cerdá, K. Ramacciotti (Eds.). La salud pública y la enfermería en la Argentina. Universidad Nacional de Quilmes, Bernal Argentina. 
34. Pereyra F, Micha A (2016) The configuration of nursing labor conditions in the Buenos Aires Metropolitan Area: An analysis at the intersection of the gender order and the organization of the health system. Salud Colect 12: 221-238. [Crossref]

35. Smith DE (2005) Institutional Ethnography: A Sociology for People. Altamira Press, Toronto.

36. McCoy L (2008) Institutional ethnography and constructionism. In: Holstein JA, Gubrium JF (eds) Handbook of Constructionist Research. Guildford Press, London.
37. Sinding C (2010) Using institutional ethnography to understand the production of health care disparities. Qual Health Res 20: 656-1663. [Crossref]

38. Burgess D (2010) Are providers more likely to contribute to healthcare disparities under high levels of cognitive load? how features of the healthcare setting may lead to biases in medical decision making. Med Decis Making 30: 246-257. [Crossref]

39. Luxardo N, Manzelli H (2017) Blurred logics behind frontline staff decision-making for cancer control in Argentina. Health Sociology Review 26: 224-238.

Copyright: (2018 Luxardo N. This is an open-access article distributed under the terms of the Creative Commons Attribution License, which permits unrestricted use, distribution, and reproduction in any medium, provided the original author and source are credited. 